\title{
Atividade antimicrobiana e antibiofilme de nanopartículas de prata sobre isolados de Aeromonas spp. obtidos de organismos aquáticos ${ }^{1}$
}

\author{
Naiana B. Freire ${ }^{2}$, Larissa C.S.R. Pires ${ }^{2}$, Helinando P. Oliveira ${ }^{3}$ e Mateus M. Costa ${ }^{2 *}$
}

\begin{abstract}
Braga N.B., Pires L.C.S.R., Oliveira H.P. \& Costa M.M. 2018. [Antimicrobial and antibiofilm activity of silver nanoparticles against Aeromonas spp. isolated from aquatic organisms.] Atividade antimicrobiana e antibiofilme de nanopartículas de prata sobre isolados de Aeromonas spp. obtidos de organismos aquáticos. Pesquisa Veterinária Brasileira 38(2):244-249. Colegiado Acadêmico de Zootecnia, Universidade Federal do Vale do São Francisco, Rodovia BR-407 Km 12, Lote 543, Projeto de Irrigação Nilo Coelho s/n, C1, Petrolina, PE 56300-000, Brazil. E-mail: mmatiuzzi@hotmail.com

The indiscriminate use of antibiotics has selected some pathogenic bacteria being multidrug-resistant, a situation that can be exacerbated by biofilms formation. Thus, silver nanoparticles (AgNPs) have been highlighted as an innovative alternative, low-cost and effective against bacterial diseases. The aim of this study was to determine the antimicrobial activity of AgNPs and the interference in Aeromonas spp. biofilm formation. The strains were obtained from aquatic organisms. The AgNPs were chemically synthesized using as reducing agent trisodium citrate and characterized by ultraviolet-visible spectroscopy (UV-Vis). The antimicrobial activity was carried out against three isolates by the microdilution broth method for determining minimum bactericidal concentration (CBM) and cultivation of CCCP, an inhibitor of the efflux pump, was carried out to complement the effect of AgNPs. Interference in the biofilm formation was performed according to the protocol and consolidated, within the resistance structure characterization by scanning electron microscopy. In the test of the $\mathrm{CBM}$, the AgNPs were unable to inactivate the growth of the isolates, while the silver nitrate obtained efficiency in different concentrations. In the efflux pump inhibitor presence the isolates were analyzed, one went from resistant to nanoparticles to sensitive. The AgNPs were effective in reducing of biofilm formation and acted on the consolidated biofilm in all tested isolates. These results indicate the silver nanoparticles to interfere with Aeromonas spp. biofilm from aquatic organisms and human bodies.

INDEX TERMS: Aeromonas spp., aquatic organisms, nanotechnology, biofilm, antimicrobial resistance, poikilotherm animals, bacterioses.
\end{abstract}

RESUMO.- $O$ uso indiscriminado de antimicrobianos tem proporcionado a algumas bactérias patogênicas a seleção de cepas multirresistentes, situação que pode ser agravada pela formação do biofilme. Desta forma, as nanopartículas de prata (AgNPs) vêm se destacando como uma alternativa

\footnotetext{
${ }^{1}$ Recebido em 9 de junho de 2016.

Aceito para publicação em 22 de dezembro de 2016.

Dissertação de mestrado com apoio FACEPE.

${ }^{2}$ Universidade Federal do Vale do São Francisco (Univasf), Rodovia BR-407 KM 12, Lote 543, Projeto de Irrigação Nilo Coelho s/n, C1, Petrolina, PE 56300-000, Brasil. *Autor para correspondência: mmatiuzzi@hotmail.com

${ }^{3}$ Universidade Federal do Vale do São Francisco (Univasf), Avenida José de Sá Maniçoba s/n, Campo Universitário, Petrolina, PE 56304-917, Brasil.
}

inovadora, de baixo custo e eficiente contra doenças causadas por bactérias. 0 objetivo deste estudo foi determinar a atividade antimicrobiana das AgNPs e a interferência na formação do biofilme de Aeromonas spp. obtidas de organismos aquáticos. As AgNPs foram sintetizadas quimicamente utilizando como agente redutor o citrato trissódico e caracterizadas por espectrofotometria ultravioleta-visível (UV-Vis). A atividade antimicrobiana foi realizada contra três isolados pelo método de microdiluição em caldo para determinar a concentração bactericida mínima (CBM) e um cultivo com CCCP, um inibidor da bomba de efluxo, foi realizado para complementar o efeito das AgNPs. A interferência no biofilme foi realizada segundo o protocolo de formação e consolidado, além da caracterização 
desta estrutura de resistência por microscopia eletrônica de varredura. No teste da CBM, as AgNPs não foram capazes de inativar o crescimento dos isolados, ao passo que o nitrato de prata obteve eficiência em diferentes concentrações. $\mathrm{Na}$ presença do inibidor de bomba de efluxo, dos isolados analisados, um passou de resistente a sensível na presença das nanopartículas. As AgNPs foram eficazes em diminuir a formação de biofilme, como também atuaram sobre o biofilme consolidado em todos os isolados testados. Estes resultados indicam o potencial das nanopartículas de prata em interferir com o biofilme de Aeromonas spp. de organismos aquáticos e seres humanos.

TERMOS DE INDEXAÇÃO: Aeromonas spp., organismos aquáticos, nanotecnologia, biofilme, antimicrobiano, resistência, animais poiquilotermos, bacterioses.

\section{INTRODUÇÃO}

O mundo microbiano está evoluindo continuamente, culminando no aparecimento de micro-organismos com uma ampla diversificação genética, sendo estes capazes de provocar diversas doenças. Apesar de existirem muitas terapias antimicrobianas disponíveis no mercado para diferentes infecções bacterianas, seu uso indiscriminado levou muitas bactérias patogênicas a adquirirem resistência (Kyriacou et al. 2004, Kim et al. 2007).

Uma das formas de resistência bacteriana é caracterizada pela formação de biofilme, que possui um mecanismo de ação bastante complexo e dinâmico, onde colônias microbianas crescem envoltas por material viscoso aderido em superfície. Nesta estrutura, os biofilmes são constituídos por água, matriz de polímeros extracelulares (exopolissacarídeos - EPS), partículas retidas e substâncias dissolvidas e adsorvidas, onde os micro-organismos passam da forma planctônica para a vida séssil (Clutterbuck et al. 2007). Assim, a busca por novas alternativas viáveis para o desenvolvimento de antimicrobianos que busquem controlar ou eliminar este tipo de resistência é urgente e necessária.

Bactérias do gênero Aeromonas, bastonetes Gram-negativos, são agentes patogênicos que causam uma variedade de doenças em humanos e principalmente em peixes, sendo considerada uma das principais causas de perdas econômicas na piscicultura (Cyrino et al. 2004, Yardimci \& Aydin 2011). Um dos principais mecanismos de patogenicidade descritos para estas bactérias é a formação de biofilmes em diversas superfícies. Neste contexto, a nanotecnologia mostra-se como uma alternativa importante, uma vez que os compostos na escala nanométrica apresentam propriedades distintas quando comparados na escala macrométrica (Fernandes 2010). As nanopartículas são substâncias com dimensões entre $1 \mathrm{e}$ 100 nanômetros (nm) e ultimamente são utilizadas na medicina e apresentam grande interesse por destruir ou reduzir a atividade de vários micro-organismos (Seil \& Webster 2012).

Dentre as nanopartículas metálicas, as de prata são as mais conhecidas por suas aplicações em diferentes áreas, como na medicina humana e veterinária, farmacologia, odontologia, indústria alimentícia, entre outras (Petica et al. 2008, Pereira et al. 2013). Existe um grande interesse na utilização das nanopartículas de prata (AgNPs), devido às suas propriedades notáveis, como área superficial elevada, excelente atividade antimicrobiana (Antunes et al. 2013) e como alternativas para redução da adesão bacteriana e prevenção da formação de biofilmes (Pereira et al. 2013). Estudos complementares são necessários para verificar o potencial das nanopartículas de prata, no intuito de desenvolver futuramente um novo antimicrobiano, contribuindo tanto para a ciência como para a qualidade de vida da sociedade.

Este estudo teve como objetivo determinar a capacidade das nanopartículas de prata em interferir no biofilme em formação e no consolidado de isolados de Aeromonas spp.

\section{MATERIAL E MÉTODOS}

Isolados bacterianos. Para o desenvolvimento do estudo utilizaram-se três isolados de Aeromonas spp. classificados como moderados produtores de biofilme. Estes isolados foram obtidos entre os anos de 2010 e 2012 a partir de lesões de tilápias (Orecohromis niloticus) (isolados P2.2 e 60) e de pool de branchonetas (Dendrocephalus brasilliensis) (isolado 1A) destinadas à alimentação de peixes carnívoros, provenientes da Barragem de Sobradinho/BA e do Projeto Bebedouro da CODEVASF/PE.

Nanopartículas de prata (AgNPs). As nanopartículas de prata foram obtidas através do método de redução química, utilizando o protocolo de Lee e Meisel (1982), que se baseia na redução do nitrato de prata $\left(\mathrm{AgNO}_{3}\right.$ - Sigma-Aldrich $\left.{ }^{\circledR} 99,0 \%\right)$ por citrato trissódico $\left(\mathrm{C}_{6} \mathrm{H}_{5} \mathrm{O}_{7} \mathrm{Na}_{3}-\right.$ Sigma-Aldrich $\left.{ }^{\circledR} 99,0 \%\right)$. Em 500mL de água deionizada, 90mg de nitrato de prata $\left(\mathrm{AgNO}_{3}\right)$ foram dissolvidos e a solução foi aquecida até ebulição, obtendo-se uma concentração de $1 \mathrm{mM}$. Em seguida, $10 \mathrm{~mL}$ da solução de citrato de trissódio a $1 \%$ foram adicionados gota a gota à solução de nitrato de prata em ebulição, acompanhada por vigorosa agitação magnética e mantida em ebulição durante aproximadamente uma hora. Em seguida, a solução foi removida do elemento de aquecimento e agitada até chegar à temperatura ambiente. Finalmente, uma prata coloidal amarelo-esverdeada foi obtida. Os espectros de absorção das nanopartículas de prata foram registados utilizando o espectrofotômetro ultravioleta-visível (UV-vis) Hach, operado numa resolução de 200-1200nm.

Análise da atividade antimicrobiana das AgNPs. A análise da atividade antimicrobiana das AgNPs foi realizada através do teste de microdiluição em caldo. A avaliação da concentração bactericida mínima (CBM) das soluções sobre os três isolados de Aeromonas spp. caracterizados como moderados produtores de biofilme foi determinada seguindo as descrições do protocolo M7-A7 do Clinical and Laboratory Standards Institute (CLSI 2006), que consiste inicialmente em sucessivas microdiluições em caldo. Primeiramente, $200 \mu \mathrm{L}$ de caldo Mueller Hinton (MH) foram distribuídos em cada poço das microplacas. Uma alíquota de $200 \mu \mathrm{L}$ da solução de nanopartículas de prata foi adicionada ao primeiro poço e, após homogeneização, transferida para o segundo, e assim sucessivamente. Uma vez realizadas as diluições seriadas, foram obtidas as seguintes diluições: $1: 1 ; 1: 2 ; 1: 4 ; 1: 8 ; 1: 16 ; 1: 32$; $1: 64 ; 1: 128 \mu \mathrm{g} / \mathrm{mL}$. 0 mesmo procedimento foi realizado com a solução de nitrato de prata $\left(\mathrm{AgNO}_{3}\right)$ (controle), obtendo-se concentrações finais de 84,$5 ; 42,25 ; 21,12 ; 10,56 ; 5,28 ; 2,64$; 1,$32 ; 0,66 \mu \mathrm{g} / \mathrm{mL}$.

Na preparação do inóculo, $5 \mathrm{~mL}$ de solução salina foram utilizados para obtenção de uma suspensão bacteriana com densidade ótica de $0,104 \mathrm{~nm}\left(10^{8}\right.$ Unidades Formadoras de Colônias), que foi mensurada em espectrofotômetro no 
comprimento de onda de $580 \mathrm{~nm}$. Desta suspensão, $100 \mu \mathrm{L}$ foram transferidos para um tubo contendo 9,9mL de caldo $\mathrm{MH}$, sendo que $10 \mu \mathrm{L}$ foram colocados em cada poço contendo as diluições das nanopartículas de prata e do nitrato de prata. As microplacas foram incubadas a $28^{\circ} \mathrm{C}$ durante 24 horas. Posteriormente, com auxílio de um replicador multicanal, o conteúdo de cada poço da microplaca foi inoculado em placas contendo Ágar MH, incubando-as novamente por mais 24 horas a $28^{\circ} \mathrm{C}$, para determinação da CBM, considerada a menor concentração das soluções em estudo capaz de causar a morte do inóculo. Como controle negativo (-) foram utilizados quatro poços com o caldo $\mathrm{MH}$ e, como controle positivo (+), foram utilizados quatro poços com o caldo $\mathrm{MH}$ e o inóculo bacteriano. Para verificar a eficiência das nanopartículas de prata, realizou-se o mesmo procedimento com um inóculo de Staphylococcus aureus. Os ensaios foram realizados em triplicata.

Interferência das AgNPs na presença do CCCP. Para avaliar a capacidade de interferência das nanopartículas na presença do inibidor de bomba de efluxo (CCCP) os isolados foram cultivados em tubos contendo $3 \mathrm{~mL}$ de caldo $\mathrm{MH}$ e incubados a $28^{\circ} \mathrm{C}$ por 24 horas. Passado esse período de incubação, foram adicionados $180 \mu \mathrm{L}$ nos três poços iniciais da microplaca referentes a cada bactéria e nos demais poços foram adicionados $100 \mu \mathrm{L}$ do meio. $20 \mu \mathrm{L}$ da solução de nanopartículas foram adicionados também nos três poços iniciais de cada bactéria e realizada a diluição seriada. Após esse procedimento acrescentou-se $20 \mu \mathrm{L}$ de CCCP 0,04 M em todos os poços. Posteriormente adicionou-se $100 \mu \mathrm{L}$ de caldo $\mathrm{MH}$ com as bactérias em todos os poços. Incubou-se por 24 horas a $28^{\circ} \mathrm{C}$. Em seguida, com auxílio do replicador de microplacas, carimbou-se uma placa contendo ágar $\mathrm{MH}$.

Interferência das nanopartículas de prata (AgNPs) na formação do biofilme e no biofilme consolidado. Para avaliar a capacidade de interferência das nanopartículas sobre o biofilme em formação de Aeromonas spp., uma alçada de cada isolado bacteriano foi cultivado em $3 \mathrm{~mL}$ de TSB por 24 horas a $28^{\circ} \mathrm{C}$. Destes cultivos, $100 \mu \mathrm{L}$ foram acrescidos nos poços de microplacas contendo $100 \mu \mathrm{L}$ da solução coloidal das nanopartículas de prata e nitrato de prata na concentração da metade do valor da CBM. Como controles negativos, foram utilizados $100 \mu \mathrm{L}$ de meio de cultura. As microplacas foram incubadas por 24 horas a $28^{\circ} \mathrm{C}$. Após este período, as amostras foram lavadas com $200 \mu \mathrm{L}$ de água destilada, três vezes. Em seguida, os poços foram corados com $100 \mu \mathrm{L}$ de violeta de genciana $0,25 \%$ por três minutos e novamente lavados com $200 \mu \mathrm{L}$ de água destilada. Posteriormente, foram adicionados 200 $\mu \mathrm{L}$ de álcool-acetona (8:2) para diluição dos cristais. Por fim, a DO (densidade ótica) foi determinada em leitor de microplaca, mensurada em $620 \mathrm{~nm}$ (Nostro et al. 2007).

$\mathrm{Na}$ avaliação da capacidade de interferência das nanopartículas de prata e do nitrato de prata sobre o biofilme já consolidado, microplacas contendo $100 \mu \mathrm{L}$ das suspensões bacterianas foram incubadas em estufa por 24 horas a $28^{\circ} \mathrm{C}$ para a formação prévia do biofilme. Após a incubação, os poços das microplacas foram lavados três vezes com $200 \mu \mathrm{L}$ de água destilada e, em seguida, foi acrescida as substâncias testes. A DO foi determinada em leitor de microplaca logo após a adição das nanopartículas (0h) (DO0h) e 24 horas depois (D024hs), mensurada em $620 \mathrm{~nm}$, sendo a interferência definida pela equação: D00h média /D024hs média x100 (Nostro et al. 2007). Para visualização microscópica do biofilme bacteriano formado, realizou-se a análise de microscopia eletrônica de varredura (MEV).

A confecção das amostras para análise de microscopia, deu-se seguindo o protocolo de formação de biofilme e interferência na presença da nanopartículas de prata (FREITAS et al. 2010). Em seguida, foi realizado o protocolo de fixação, onde: $10 \mu \mathrm{L}$ da solução bacteriana com e sem adição das nanopartículas de prata foram colocados em uma lâmina contendo uma fita de cobre. Posteriormente, foi realizado o procedimento de fixação: duas horas e 30 minutos no glutaraldeído 1\%; 20 minutos em imersão crescente de etanol (50, 70, 80, 95, 100\%); 5 minutos em acetona $100 \%$.

\section{RESULTADOS E DISCUSSÃO}

\section{Síntese e caracterização das nanopartículas}

As nanopartículas de prata obtidas a partir da síntese química foram caracterizadas essencialmente por espectrofotometria ultravioleta-visível, que é uma técnica muito útil para a análise de nanopartículas. A leitura da solução coloidal das nanopartículas de prata no espectrofotômetro UV-Vis indicou um pico de comprimento de onda de aproximadamente $420 \mathrm{~nm}$ (Fig.1). A prata (Ag) apresenta uma absorção de luz na faixa de comprimento de onda 390 a 450nm (Kim et al. 2007).

Os diâmetros das nanopartículas de prata resultantes da síntese dependem de diferentes condições, tais como o tipo do agente redutor, a quantidade e a concentração destes, bem como a temperatura de reação, a velocidade de agitação e a duração do processo de redução (Solomon et al. 2007).

\section{Análise da atividade antimicrobiana das AgNPs}

As nanopartículas de prata não apresentaram efeito antimicrobiano sobre os isolados de Aeromonas spp. testados, porém o nitrato de prata inativou o crescimento dos isolados nas concentrações bactericidas mínimas de 2,64 $\mathrm{g} \backslash \mathrm{mL}$ para um isolado (P2.2) e de 5,28 $\mu \mathrm{g} \backslash \mathrm{mL}$ para os demais. A prata na forma de nanopartículas é mais reativa por apresentar propriedades físico-químicas únicas, e o aumento de suas propriedades catalíticas a tornaria mais tóxica do que seu

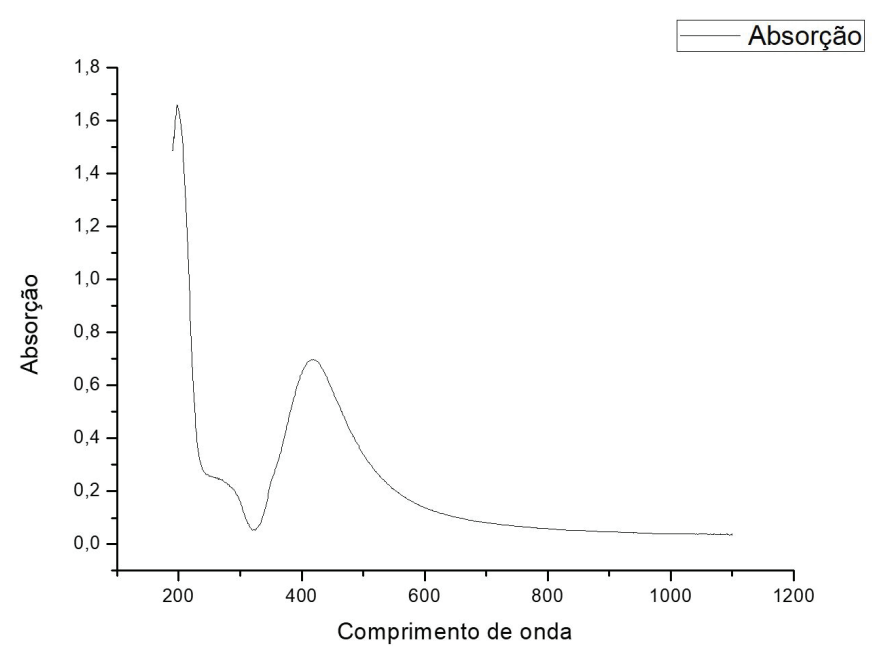

Fig.1. Espectroscopia UV-Vis da solução coloidal das nanopartículas de prata. 
equivalente na escala macroscópica (Fernandes 2010). Contudo, neste estudo, observou-se efeito contrário.

Para verificar se a ineficiência das nanopartículas de prata utilizada está relacionada com a baixa concentração de prata na solução coloidal, foi feito o teste da CBM sobre um isolado de Staphylococcus aureus, já que na literatura consta que esta bactéria é bem sensível a estas nanopartículas (Feng et al. 2000, Soo-Hwan, 2011, Mohanty et al. 2012). Como resultado, as nanopartículas não inativaram o crescimento do isolado. Assim, como não foi possível determinar a concentração e o tamanho das nanopartículas neste estudo, a ineficiência das mesmas em inativar o crescimento dos isolados de Aeromonas spp., de acordo com os resultados da CBM, pode estar relacionada a estes fatores. Segundo Antunes et al. (2013), a baixa concentração das nanopartículas de prata na solução coloidal pode ter contribuído para o resultado obtido em seu ensaio. Porém, ao aumentar a concentração são necessários estudos complementares sobre a toxicidade das nanopartículas de prata para que possam ser aplicadas em animais.

\section{Interferência das nanopartículas na presença do CCCP}

No teste com o inibidor de bomba de efluxo (CCCP) na presença das nanopartículas de prata, dos três isolados (moderados produtores de biofilme) avaliados nesse estudo que eram resistentes às nanopartículas, um demonstrou sensibilidade na concentração utilizada. Esse resultado pode sugerir que a resistência a essas nanopartículas está relacionada com a atividade de bombas de efluxo, sendo que na presença do inibidor as bactérias se tornaram sensíveis à solução de nanopartículas utilizadas no teste.

Smith et al. (2008) através de estudos realizados com peixes, mostrou que no ambiente aquático a troca de genes de resistência é estimulada devido à fácil movimentação dos micro-organismos e elementos genéticos móveis como os plasmídeos. Yates et al. (2004) por sua vez, reforçam essa afirmação ao demonstrarem que existe uma associação direta da resistência bacteriana aos antimicrobianos e metais pesados para diversos genes de resistência que são codificados em plasmídeos. Isto poderia justificar o resultado observado em um dos isolados utilizados, o qual passou de resistente a sensível com a utilização do inibidor de bomba de efluxo. Entretanto, são necessários outros estudos para verificar com maior acurácia outras possíveis causas para os resultados diferentes entre os isolados analisados pelo presente trabalho, o que ainda não foi encontrado na literatura, uma vez que os estudos sobre a utilização de bombas de efluxo em Aeromonas spp. ainda são insipientes.

\section{Interferência das nanopartículas no biofilme em formação e no biofilme consolidado}

As nanopartículas de prata interferiram no biofilme de todos os isolados avaliados. Aliado ao fato de que os antimicrobianos geralmente agem na fase do crescimento bacteriano, como síntese proteica, síntese de ácidos nucléicos e de parede celular (Tretin et al. 2013), a ação de um antibiofilme visa ao controle direto do biofilme, agindo na matriz de exopolissacarídeos (EPS), mais especificamente na estabilidade estrutural, composta de pontes iônicas de íons de cálcio e de magnésio, e no enovelamento de cadeias vizinhas de polissacarídeos, inibindo desde a sua formação até à destruição de um biofilme já consolidado (Wingender et al. 1999).

Não existem evidências quanto aos mecanismos de descolamento e inibição do biofilme, porém suspeita-se que o potencial antibiofilme das nanopartículas pode estar associada ao seu tamanho extremamente pequeno (Morones et al. 2005) e a penetração da prata através dos poros presentes na camada de EPS (Sondi \& Salopek-Sondi 2004). Em estudos desenvolvidos por Kalishwaralal et al. (2010), Pseudomonas aeruginosa e Staphylococcus epidermidis continuaram crescendo em baixas concentrações (50nM) de nanopartículas de prata, mas suas capacidades para sintetizar o EPS foram bloqueadas. Ao aumentar a concentração das nanopartículas para $100 \mathrm{nM}$, estas não só inibiram efetivamente o crescimento das bactérias, como também interferiram no biofilme já consolidado. Os íons de prata podem difundir diretamente na camada EPS através dos poros, exercendo sua função antimicrobiana (Kalishwaralal et al. 2010). Desta forma, a concentração das nanopartículas utilizadas deveria ser bem maior para que estas após interferir no biofilme, inativasse o crescimento dos isolados do gênero Aeromonas.

Uma vez que a produção de biofilme por isolados de Aeromonas spp. foi quantificada, os três isolados classificados como moderados produtores de biofilme foram submetidos a estes ensaios, por representarem os isolados passíveis de avaliação mais precisa. Tanto as nanopartículas de prata quanto o nitrato de prata foram capazes de diminuir a formação do biofilme por todos os isolados (Quadro 1). Porém, em termos de inibição total do biofilme (negativo), as nanopartículas foram mais eficientes.

Chaw et al. (2005) realizaram um estudo que tinha como objetivo verificar a ação reativa de íons de prata e investigar o papel destes íons em desestabilizar as forças de adesão intercelular em biofilmes de $S$. epidermidis, utilizando microscopia de força atômica (AFM). Após a adição de íons de prata, e dentro de 60 minutos de contato, a estrutura geral do biofilme tornou-se parcialmente destruída e a estrutura interna foi exposta. Com base nesta reatividade dos íons de prata como doador de elétrons, acredita-se que os íons de prata têm um efeito considerável sobre a estabilidade global da EPS (Chaw et al. 2005). Resultado semelhante foi relatado por Feng et al. (2000), onde as nanopartículas de prata apresentaram efeito contra o biofilme de P. aeruginosa através da inibição da síntese da EPS.

No teste de interferência sobre o biofilme já consolidado, as nanopartículas de prata também apresentaram maior eficiência, obtendo uma média de interferência de 38,2\%. Desta forma, acredita-se que as nanopartículas de prata possuem relevante atividade sobre o biofilme de Aeromonas spp. já consolidado.

Quadro 1. Classificação dos isolados de Aeromonas spp. quanto à produção de biofilme em contato com as AgNPs e o $\mathrm{AgNO}_{3}$ nos ensaios de inibição do biofilme em formação

\begin{tabular}{llll}
\hline $\mathrm{P}_{2.2}$ & Moderado & Fraco & Fraco \\
\hline 60 & Moderado & Fraco & Fraco \\
\hline $1 \mathrm{~A}$ & Moderado & Fraco & Fraco \\
\hline
\end{tabular}



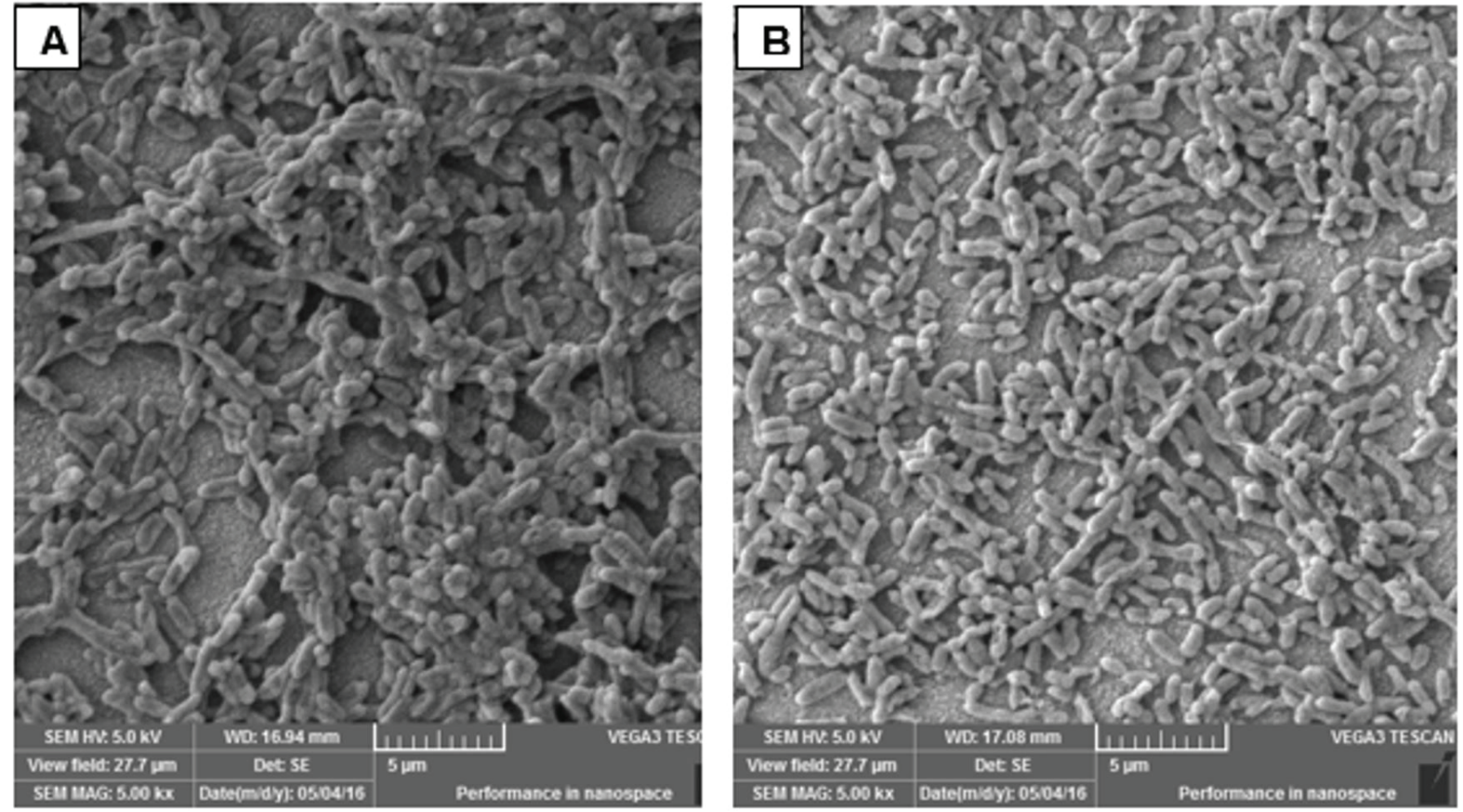

Fig.2. Imagem de microscopia eletrônica de varredura de biofilme de Aeromonas spp. (A) sem e (B) com adição de nanopartículas de Ag.

Com o objetivo de testar o efeito de diferentes concentrações das nanopartículas de prata no biofilme já consolidado por $P$. aeruginosa e $S$. aureus sob condições in vitro, monitorando em 24 e 48 horas, Mohanty et al. (2012) chegaram à conclusão que o tratamento de 24 horas resultou numa diminuição de mais de $50 \%$ e de $85 \%$ na formação do biofilme nas concentrações de $1 \mu \mathrm{M}$ e $2 \mu \mathrm{M}$, respectivamente, ao passo que o tratamento de 48 horas reduziu em aproximadamente $65 \%$ e $88 \%$ a formação do biofilme nas concentrações de $1 \mu \mathrm{M}$ e $2 \mu \mathrm{M}$, respectivamente. Chandra et al. (2001) atribuiu a maior resistência das nanopartículas de prata no biofilme já consolidado à maior presença do EPS, pois no biofilme em formação as células são mais jovens, apresentando um metabolismo mais ativo, o que corrobora com os resultados deste estudo. Para causar a morte das bactérias inseridas no biofilme consolidado, a concentração ideal seria 1.000 vezes maior do que nas células planctônicas (Clutterbuck et al. 2007).

$\mathrm{Na}$ análise de microscopia eletrônica de varredura as amostras acrescidas da solução de nanopartículas apresentaram uma discreta desagregação celular (Fig.2). Não foi possível observar diferenças expressivas no biofilme entre os isolados bacterianos puros e acrescidos de nanopartículas. Provavelmente, isso se deve ao fato de os isolados utilizados no estudo serem moderados formadores de biofilme. Acredita-se que, se fossem fortes formadores de biofilme, a diferença seria mais facilmente evidenciada. Dados revelam que nanopartículas de prata promovem a destruição da matriz de exopolissacarídeos do biofilme em bactérias gram negativas, porém as concentrações que inibem a formação de biofilme não são suficientes para matar as células bacterianas (Radzig et al. 2013).

Estudos indicam que as substâncias antibiofilme pode ser combinado com um antibiótico convencional para controlar eficientemente a formação do biofilme, bem como perturbar o biofilme já consolidado, permitindo que a droga consiga atingir as células bacterianas que vivem em seu interior (Abraham et al. 2011). Existem trabalhos na literatura que mostram que o tratamento combinando nanopartículas de prata e antibióticos possui uma excelente eficiência (Birla et al. 2009, Gurunathan et al. 2014). Muitos antibióticos, tais como ampicilina, gentamicina, canamicina, estreptomicina e vancomicina foram testados com AgNPs, e as atividades antibacterianas destes antibióticos foram aumentadas contra os micro-organismos gram-negativos Escherichia coli e P. aeruginosa, em comparação com S. aureus (Birla et al. 2009). Nanopartículas metálicas também podem ser combinadas com polímeros para formar compostos com uma maior atividade antimicrobiana (Ruparelia et al. 2008).

\section{CONCLUSÕES}

As nanopartículas de prata não foram capazes de inativar o crescimento do isolados de Aeromonas spp., podendo indicar que a solução coloidal utilizada apresenta baixa concentração de prata. Desta forma, mais estudos são necessários para verificar a concentração ideal que cause a inativação do crescimento bacteriano, desde que não seja tóxico para seu hospedeiro.

0 teste com o inibidor de bomba de efluxo (CCCP) teve efeito inibitório em um dos isolados analisados, o que comprova que a resistência a essas nanopartículas está relacionada com a atividade de bombas de efluxo.

Apesar das nanopartículas não apresentarem efeito inibitório no crescimento dos isolados, foi constatado que a mesma apresentou um grande potencial de ação antibiofilme quando utilizada para interferir no biofilme em formação, bem como no biofilme já consolidado.

Novos ensaios devem ser realizados para aprimorar a ação das nanopartículas de prata, combinando-as com outros compostos para que, além das mesmas exibirem ação 
antibiofilme, possam apresentar potencial antimicrobiano, já que terapias antimicrobianas para Aeromonas spp. são bastante limitadas.

\section{REFERÊNCIAS}

Abraham S.V.P.I., Palani A., Ramaswamy B.R., Shunmugiah K.P. \& Arumugam V.R. 2011. Antiquorum sensing and antibiofilm potential of Capparis spinosa. Arch. Med. Res. 42(8):658-668. PMid:22222491. http://dx.doi.org/10.1016/j. arcmed.2011.12.002.

Antunes F.S., Dal'acqua N., Bergmann C.P. \& Giovanela M. 2013. Síntese, caracterização e aplicação de nanopartículas de prata como agentes antimicrobianos. Estud. Tecnol. Eng. 9(1):20-26.

Baker-Austin C., Wright M.S., Stepanauskas R. \& McArthur J.V. 2006. Coselection of antibiotic and metal resistance. Trends Microbiol. 14(4):176-182. PMid:16537105. http://dx.doi.org/10.1016/j.tim.2006.02.006.

Birla S.S., Tiwari V.V., Gade A.K., Ingle A.P., Yadav A.P. \& Rai M.K. 2009. Fabrication of silver nanoparticles by Phoma glomerata and its combined effect against Escherichia coli, Pseudomonas aeruginosa and Staphylococcus aureus. Lett. Appl. Microbiol 48(2):173-179. PMid:19141039. http://dx.doi.org/10.1111/j.1472765X.2008.02510.x.

Chandra I., Kuhn D.M., Mukherjee P.K., Hoyer L.L., Mccormick T. \& Ghannoum M.A. 2001. Biofilm formation by the fungal pathogen Candida albicans: development, architecture and drug resistance. J. Bacteriol. 183(18):53855394.PMid:11514524.http://dx.doi.org/10.1128/JB.183.18.5385-5394.2001.

Chaw K.C., Manimaran M. \& Tay F.E. 2005. Role of silver ions in destabilization of intermolecular adhesion forces measured by atomic force microscopy in Staphylococcus epidermidis biofilms. Antimicrob. Agents Chemother. 49(12):48534859. PMid:16304145. http://dx.doi.org/10.1128/AAC.49.12.4853-4859.2005.

CLSI 2006. Methods for dilution antimicrobial susceptibility tests for bacteria that grow aerobically. Clinical and Laboratory Standards Institute. Wayne, Pennsylvania. Disponível em <http://www.clsi.org/> Acesso em 12 jun. 2015.

Clutterbuck A.L., Woods E.J., Knottenbelt D.C., Clegg P.D., Cochrane C.A. \& Percival S.L. 2007. Biofilms and their relevance to veterinary medicine. Vet. Microbiol. 121(1-2):1-17.PMid:17276630. http://dx.doi.org/10.1016/j.vetmic.2006.12.029.

Cyrino J.E.P., Urbinati E.C., Fracalossi D.M. \& Castagnolli N. 2004. Tópicos Especiais em Piscicultura de Água Doce Tropical Intensiva. TecArte, São Paulo. 533p.

Feng Q.L., Wu J., Chen G.Q., Cui F.Z., Kim T.N. \& Kim J.0. 2000. A mechanistic study of the antibacterial effect of silver ions on Escherichia coli and Staphylococcus aureus. J. Biomed. Mater. Res. 52(4):662-668. PMid:11033548. http://dx.doi. org/10.1002/1097-4636(20001215)52:4<662::AID-JBM10>3.0.CO;2-3.

Fernandes P.E. 2010. Novo método de síntese de nanopartículas de prata e avaliação de seu efeito antimicrobiano. Dissertação de Mestrado em Ciências, Universidade Federal de Viçosa, Viçosa, MG. 59p.

Freitas V.R., Van der Sand S.T. \& Simonetti A.B. 2010. In vitro biofilm formation by Pseudomonas aeruginosa and Staphylococcus aureus on the surface of high-speed dental handpieces. Rev. Odontol. 39(4):193-200.

Gurunathan S., Han J.W., Kwon D.N. \& Kim J.H. 2014. Enhanced antibacterial and anti-biofilm activities of silver nanoparticles against Gram-negative and Gram-positive bactéria. Nanoscale Res. Lett. 9(1):373.PMid:25136281. http:// dx.doi.org/10.1186/1556-276X-9-373.

Kalishwaralal K., Barathmanikanth S., Pandian S.R.K., Deepak V. \& Gurunathan S. 2010. Silver nanoparticles impede the biofilm formation by Pseudomonas aeruginosa and Staphylococcus epidermidis. Colloids Surf. B Biointerfaces 79(2):340-344. PMid:20493674. http://dx.doi.org/10.1016/j.colsurfb.2010.04.014.

Kim J.S., Kuk E., Yu K.N., Kim J.H., Park S.J., Lee H.J., Kim Y.K., Park Y.K., Park Y.H., Hwang C.Y., Kim Y.K., Lee Y.S., Jeong D.H. \& Cho M.H. 2007. Antimicrobial effects of silver nanoparticles. Nanomed. Nanotech. Biol. Med. 3(1):95-101. PMid:17379174. http://dx.doi.org/10.1016/j.nano.2006.12.001.

Kyriacou S.V., Brownlow W.J. \& Xu X.N. 2004. Using nanoparticle optics assay for direct observation of the function of antimicrobial agents in single live bacterial cells. Biochemistry 43(1):140-147. PMid:14705939. http://dx.doi. org/10.1021/bi0351110.

Lee P.C. \& Meisel D. 1982. Adsorption and surface-enhanced raman of dyes on silver and gold sols. J. Phys. Chem. US 86(17):3391-3395. http://dx.doi. org/10.1021/j100214a025.

Mohanty S., Mishra S., Jena P., Jacob B., Sarkar B. \& Sonawane A. 2012. An investigation on the antibacterial, cytotoxic, and antibiofilm efficacy of starchstabilized silver nanoparticles. Nanomed. Nanotech. Biol. Med. 8(6):916-924. PMid:22115597. http://dx.doi.org/10.1016/j.nano.2011.11.007.

Morones J.R., Elechiguerra J.L., Camacho J., Holt K., Kouri J.B., Ramírez J.T. \& Yacaman M.J. 2005. The bactericidal effect of silver nanoparticles. Nanotechnology 16(10):2346-2353. PMid:20818017. http://dx.doi.org/10.1088/0957$4484 / 16 / 10 / 059$

Mulfinger L., Solomon S.D., Bahadory M., Jeyarajasingam A.V., Rutkowsky S.A. \& Boritz C. 2007. Synthesis and study of silver nanoparticles. J. Chem. Educ. 84(2):322-335. http://dx.doi.org/10.1021/ed084p322.

Nostro A., Sudano Roccaro A., Bisignano G., Marino A., Cannatelli M.A., Pizzimenti F.C., Cioni P.L., Procopio F. \& Blanco A.R. 2007. Effects of oregano, carvacrol and thymol on Staphylococcus aureus and Staphylococcus epidermidis biofilms. J. Med. Microbiol.56(Pt4):519-523.PMid:17374894.http://dx.doi.org/10.1099/ jmm.0.46804-0.

Pereira A.A., Araújo E.A., Ribeiro L., Passos F.R., Botrel D.A., Bernardes P.C. \& Andrade N.J.D. 2013. Otimização da produção de nanopartículas de prata utilizando nova síntese e avaliação da sua ação sanitizante. Biosci. J. 29(2):506-515.

Petica A., Gavriliu S., Lungu M., Buruntea N. \& Panzaru C. 2008. Colloidal silver solutions with antimicrobial properties. Mater. Sci. Eng. 152(1-3):22-27. http://dx.doi.org/10.1016/j.mseb.2008.06.021.

Radzig M.A., Nadtochenko V.A., Koksharova O.A., Kiwi J., Lipasova V.A. \& Khmel I.A. 2013. Antibacterial effects of silver nanoparticles on gram-negative bacteria: Influence on the growth and biofilms formation, mechanisms of action. Colloids Surf. B Biointerfaces 102:300-306. PMid:23006569. http:// dx.doi.org/10.1016/j.colsurfb.2012.07.039.

Ruparelia J.P., Chatterjee A.K., Duttagupta S.P. \& Mukherji S. 2008.Strain specificity in antimicrobial activity of silver and copper nanoparticles. Acta Biomater 4(3):707-716. PMid:18248860. http://dx.doi.org/10.1016/j.actbio.2007.11.006

Seil J.T. \& Webster T.J. 2012. Antimicrobial applications of nanotechnology: methods and literature. Int. J. Nanomedicine 7:2767-2781. PMid:22745541.

Smith P.R., Breton A.L., Horsberg T.E. \& Corsin F. 2008. Guidelines for antimicrobial use in aquaculture. In: Guardabassi, L.; Jensen, L. B.; Kruse, H. Ed. Guide to Antimicrobial Use in Animals. Blackwell Publishing, p.207-216.

Sondi I. \& Salopek-Sondi B. 2004. Silver nanoparticles as antimicrobial agent: a case study on E-coli as a model for Gram-negative bacteria. J. Colloid. Interface.Sci. 275(1):177-182. PMid:15158396. http://dx.doi.org/10.1016/j. jcis.2004.02.012.

Soo-Hwan K. 2011. Antibacterial activity of silver-nanoparticles against Staphylococcus aureus and Escherichia coli. Korean J. Microbiol. Biotech. 39(1):77-85.

Trentin D.S., Giordani R.B. \& Macedo A.J. 2013. Biofilmes bacterianos patogênicos: aspectos gerais, importância clínica e estratégias de combate. Revta Liberato 14(22):113-238.

Wingender J., Neu T.R. \& Felmming H.C. 1999. Microbial Extracellular Polymeric Substances: characterization, structure and function. Springer, Berlin Heidelberg.

Yardimci B. \& Aydin Y. 2011. Pathological findings of experimental Aeromonas hydrophila infection in Nile tilapia (Oreochromis niloticus). Ankara Üniv. Vet. Fak. Derg. 58:47-54. http://dx.doi.org/10.1501/Vetfak_0000002448.

Yates C.M., Pearce M.C., Woolhouse M.E. \& Amyes S.G. 2004. High frequency transfer and horizontal spread of apramycin resistance in calf faecal Escherichia coli. J. Antimicrob. Chemother. 54(2):534-537. PMid:15231771. http://dx.doi. org/10.1093/jac/dkh353. 